\title{
Assessing the evolution of scientific publications in orthopedics journals from mainland China, Hong Kong, and Taiwan: a 12-year survey of the literature
}

Hua Jiang ${ }^{1}$, Bingjin Nong ${ }^{2}$, Lijing Yang ${ }^{1}$, Shaohui Zong ${ }^{1}$, Xinli Zhan ${ }^{1}$, Qingjun Wei ${ }^{1}$ and Zengming Xiao ${ }^{1 *}$

\begin{abstract}
Background: In China, the field of orthopedics has experienced significant growth over the past 12 years. However, the recent status of research on orthopedics among individuals in mainland China, Hong Kong, and Taiwan is unknown. In this study, we investigated characteristics and trends of orthopedics publications from these three regions.

Methods: Between 2003 and 2014, all articles published in 63 orthopedics journals originating from mainland China, Hong Kong, and Taiwan were identified via Science Citation Index Expanded (SCIE) database. A survey was conducted to systematically analyze the published orthopedics articles from the three regions according to the numbers of articles, study design, impact factors (IFs), citations, most prolific authors, and institutions. Additionally, we evaluated global trends in orthopedics publications, and ranked top 10 countries in terms of the total number of published articles over 12 years and the number of published articles per year.

Results: A total number of 123,317 articles were published in the 63 orthopedics journals between 2003 and 2014. The worldwide number of annually published orthopedics articles tended to increase during the study period. The total number of orthopedics publications from the three regions, especially in mainland China, increased markedly from 2003 to 2014. The annual number of orthopedics articles from mainland China increased from 6 in 2003 to 813 in 2014, Hong Kong increased from 32 in 2003 to 71 in 2014, and Taiwan increased from 68 in 2003 to 168 in 2014. For accumulated IFs and total citations of articles, mainland China ranked the first place, followed by Taiwan and Hong Kong. However, publications from Taiwan had the highest average citations per article, and publications from Hong Kong had the highest average IFs. Among the top 10 most prolific authors and institutions, 4 authors and 4 institutions were from Taiwan, 3 authors and 4 institutions were from mainland China, and 3 authors and 2 institutions were from Hong Kong.

Conclusions: The quantity of articles published in international orthopedics journals from mainland China presented a remarkable upward trend during the past 12 years. Given the relative size of the populations, it should be emphasized that mainland China still has a long way to go to achieve the academic performance of Hong Kong and Taiwan.
\end{abstract}

Keywords: China, Medical publication, Orthopedics, Research

\footnotetext{
* Correspondence: gxspine@163.com

${ }^{1}$ Department of Orthopedic Surgery, The First Affiliated Hospital of Guangxi

Medical University, Shuangyong Road No. 6, Nanning 530021, China

Full list of author information is available at the end of the article
} 


\section{Background}

Over the past 30 years, China has scored impressive economic and cultural achievements since the adoption of the reform and opening up policy. With rapid socioeconomic development of China, great changes have taken place in science and medicine during the past decade [1]. The number of scientific papers published annually from China ranked second in the world after 2006 [2]. During the same period, Chinese orthopedics research productivity has flourished, and has got more international attention [3].

Bibliometric analyses provide significant advantages for the identification of the quantity and quality of publications from a specific country. These insights may be helpful to benchmark our scientific output and aid the allocation of future research funding [4]. Thus, bibliometrics to measure scientific productivity has been more notable in recent years. Self-assessment of the orthopedics publication from individual countries has been reported by Turkey and Japan $[5,6]$. However, information regarding Chinese scientific contribution in the field of orthopedics is still lacking. The purpose of this study is to investigate the evolution of orthopedics studies in mainland China, Hong Kong, and Taiwan, by analyzing the trends and characteristics of the scientific articles published in orthopedics journals.

\section{Methods}

In the present study, a total of 65 orthopedics journals were selected from the Science Citation Index (SCI) and Science Citation Index Expanded (SCIE) database. The selection criteria, as previous studies described [7], included that the journal met all of the following requirements: (1) was listed in the "orthopedics" category of SCI or SCIE for 2014; (2) was indexed in the PubMed database; and (3) had impact factors (IFs) according to Thomson Reuters Journal Citation Reports (JCR) 2014. The Bone \& Joint Journal, which did not have an IF in JCR 2014, and Osteologie, which was not indexed by PubMed, were excluded from this study. A computerized literature search was conducted using the "PubMed" and "Web of Knowledge" databases on September 1st, 2015, and the articles published from January 1st 2003 to December 31st 2014 in these journals were retrieved. The orthopedics articles from mainland China, Hong Kong, and Taiwan were identified using the first author's institutional affiliations. The full journal titles or the ISSN numbers of the journals were used to perform this search. The search terms used were “0363-5465 OR 1063-4584 OR 0021-9355 OR 0031-9023 OR 0749-8063 OR 0736-0266 OR 1836-9553 OR 0009921X OR 0942-2056 OR 0301-620X OR 1529-9430 OR 0940-6719 OR 0020-1383 OR 1745-3674. OR 0362-2436 OR 1067-151X OR 0190-6011 OR 0883-5403 OR 10582746 OR 0966-6362 OR 1753-1934 OR 0341-2695 OR 1050-642X OR 0300-8207 OR 1471-2474 OR 1536-0652
OR 0268-0033 OR 1757-1146 OR 0894-1130 OR 09680160 OR 0030-5898 OR 0363-5023 OR 1071-1007 OR 1749-799X OR 0890-5339 OR 0091-3847 OR 0271-6798 OR 0936-8051 OR 1877-0568 OR 0309-3646 OR 07490712 OR 1053-8127 OR 0949-2658 OR 1413-3555 OR 1067-2516 OR 0147-7447 OR 1083-7515 OR 1120-7000 OR 0085-4530 OR 1060-152X OR 1305-8282 OR 00195413 OR 1864-6697 OR 0744-6020 OR 8750-7315 OR 0934-6694 OR 0001-6462 OR 1017-995X OR 2000-656X OR 0973-6042 OR 0891-8422 OR 0001-5415 OR 09593020 OR 0932-0555 OR 1413-7852” AND “Hong Kong [ad]," "Taiwan [ad]," and "China [ad] NOT Hong Kong [ad] NOT Taiwan [ad]." Publication type of clinical studies were classified into clinical trials, randomized controlled trials (RCTs), and case reports, and were calculated using data obtained from the PubMed.

Systematic analyses have been performed on included orthopedics articles. First, we acquired and compiled the information of scientific literature from the three regions of China based on the JCR 2014 [8], which contained accumulated and average IFs of publications, citations of articles, publication type of clinical research, distribution of contributing regions. Then, we analyzed these data from the three regions of China. Second, we quantified the articles published in top 10 orthopedics journals with the highest IFs, and selected the top 10 popular orthopedics journals for the three regions in terms of the number of published articles, and ranked the most prolific authors/institutions according to the number of articles and citations. Moreover, we calculated the total and annual numbers of published orthopedics articles worldwide, and ranked top 10 countries in terms of the total number of published articles over 12 years and the number of published articles per year. Two reviewers $(\mathrm{HJ}$ and $\mathrm{BN})$ independently extracted the articles. When disagreement existed between the two reviewers, a third reviewer $(\mathrm{ZX})$ was consulted to resolve.

\section{Statistical analyses}

Statistical analyses were performed using SPSS 20.0 software (IBM, New York, USA), and the statistical results are shown as Tables and Figures. The Kruskal-Wallis test and the Mann-Whitney test were used to detect differences between regions. The trends with respect to the number of articles were analyzed via curvilinear regression. Significance was tested using the two-tailed test, and $P<0.05$ was considered significant.

\section{Results}

\section{Global trends in orthopedics publications}

A total number of 123,317 articles were published in the 63 orthopedics journals from 2003 to 2014. The worldwide number of annually published orthopedics articles tended to increase during the study period. The United 
States of America (USA) ranked the highest in the number of published orthopedics articles (36,893 articles), followed by the UK (6886), Japan (5867), China (5521), Germany (4356), Canada (3732), South Korea (2939), the Netherlands (2432), Australia (2355), and Turkey (2019). Based on the number of published articles per year, top 10 countries were described in Table 1 .

\section{Total number of articles}

Of the 123,317 published orthopedics articles, 5521 $(4.48 \%)$ were from these three regions (Fig. 1), including mainland China (3235/5521, $58.6 \%$ ), Hong Kong (700/5521, $12.7 \%)$, and Taiwan (1586/5521, $28.7 \%)$. The annual number of articles from the three regions increased significantly from 2003 to 2014 (mainland China 6 to $813, R^{2}=0.894, \quad P<0.0001$; Hong Kong 32 to $71, R^{2}=0.430, P=0.022$; Taiwan: 68 to $168, R^{2}=0806, P<0.0001$; Fig. 2$)$. The annual number of articles from mainland China has exceeded that from Hong Kong since 2007 and surpassed that from Taiwan in 2009. During the past decade, the number of articles from Taiwan and Hong Kong remained approximately 150 and below 80 , respectively. The worldwide share of articles from mainland China increased significantly over time $\left(R^{2}=0.941, P<0.0001\right)$, but this was not the case for articles from Taiwan $\left(R^{2}=0.018, P=0.987\right)$ and Hong Kong $\left(R^{2}=0.224, P=0.115\right.$; Fig. 3).

\section{Clinical trials, randomized controlled trials, and case reports}

The total quantity of published RCTs differed significantly among the three regions $(P=0.015)$. The number of RCTs published per year from mainland China has led the three regions since 2010, and even surpassed the combined number of RCTs published per year from Hong Kong and
Taiwan. The number of published clinical trials from mainland China was more than those from Hong Kong or Taiwan (mainland China vs. Hong Kong, $P=0.003$; mainland China vs. Taiwan, $P=0.137$; Hong Kong vs. Taiwan, $P=0.009$ ). Researchers from mainland China published 247 case reports between 2003 and 2014, which far exceeded those from Taiwan $(n=186, P=0.02)$ and Hong Kong $(n=76, P<0.001)$. The number of case reports from Taiwan was significantly higher than that from Hong Kong $(P=0.001)$ (Fig. 4).

\section{Impact factors}

In the current study, the 63 orthopedics journals had IFs based on the JCR 2014 [8]. The accumulated IFs of the articles from mainland China were much higher than those from Taiwan and Hong Kong (6197.33 vs. 3521.78 vs. 1871.46 , all $P$ values were less than 0.001 ). However, the average IFs of the articles from mainland China were much lower than those from Hong Kong and Taiwan ( 2.20 vs. 2.39 vs. $2.43, P<0.001)$. Hong Kong and Taiwan did not differ significantly in terms of average IFs of articles $(P>0.05)$ (Table 2$)$.

\section{Citations of published articles}

Orthopedics articles from mainland China were cited the highest number of times (18723), followed by the Taiwan (15760) and Hong Kong (8346). These differences among the three regions were significant $(P=0.007)$. A higher average per article citation was exhibited in the articles from Hong Kong (11.92) (8346 citations/700 articles) compared to those from Taiwan (9.94) (15760 citations/ 1586 articles) and mainland China (5.79) (18723 citations/ 3235 articles). This difference was statistically significant $(P=0.027)$ (Table 3$)$.

Table 1 Top 10 countries according to the annual number of articles from 2003 to 2014

\begin{tabular}{|c|c|c|c|c|c|c|c|c|c|c|}
\hline Year & 1 & 2 & 3 & 4 & 5 & 6 & 7 & 8 & 9 & 10 \\
\hline 2003 & USA & United Kingdom & Japan & Germany & Canada & France & Australia & Switzerland & Netherlands & Turkey \\
\hline 2004 & USA & United Kingdom & Japan & Germany & Canada & France & Australia & Switzerland & Turkey & Netherlands \\
\hline 2005 & USA & United Kingdom & Japan & Germany & Canada & France & Australia & Netherlands & Turkey & Switzerland \\
\hline 2006 & USA & United Kingdom & Japan & Germany & Canada & France & Switzerland & Sweden & Australia & Netherlands \\
\hline 2007 & USA & United Kingdom & Japan & Germany & Canada & France & Australia & Netherlands & South Korea & Turkey \\
\hline 2008 & USA & United Kingdom & Japan & Germany & Canada & France & Turkey & South Korea & Netherlands & Australia \\
\hline 2009 & USA & United Kingdom & Japan & Germany & Canada & France & South Korea & Turkey & Netherlands & China \\
\hline 2010 & USA & United Kingdom & Japan & Germany & Canada & Netherlands & France & Australia & China & South Korea \\
\hline 2011 & USA & United Kingdom & Japan & Germany & China & Canada & South Korea & Australia & France & Switzerland \\
\hline 2012 & USA & United Kingdom & China & Japan & Germany & South Korea & Canada & Netherlands & Australia & Italy \\
\hline 2013 & USA & United Kingdom & China & Japan & Germany & South Korea & Canada & Netherlands & Australia & Switzerland \\
\hline 2014 & USA & United Kingdom & China & Japan & Germany & Canada & South Korea & Netherlands & Italy & Australia \\
\hline
\end{tabular}




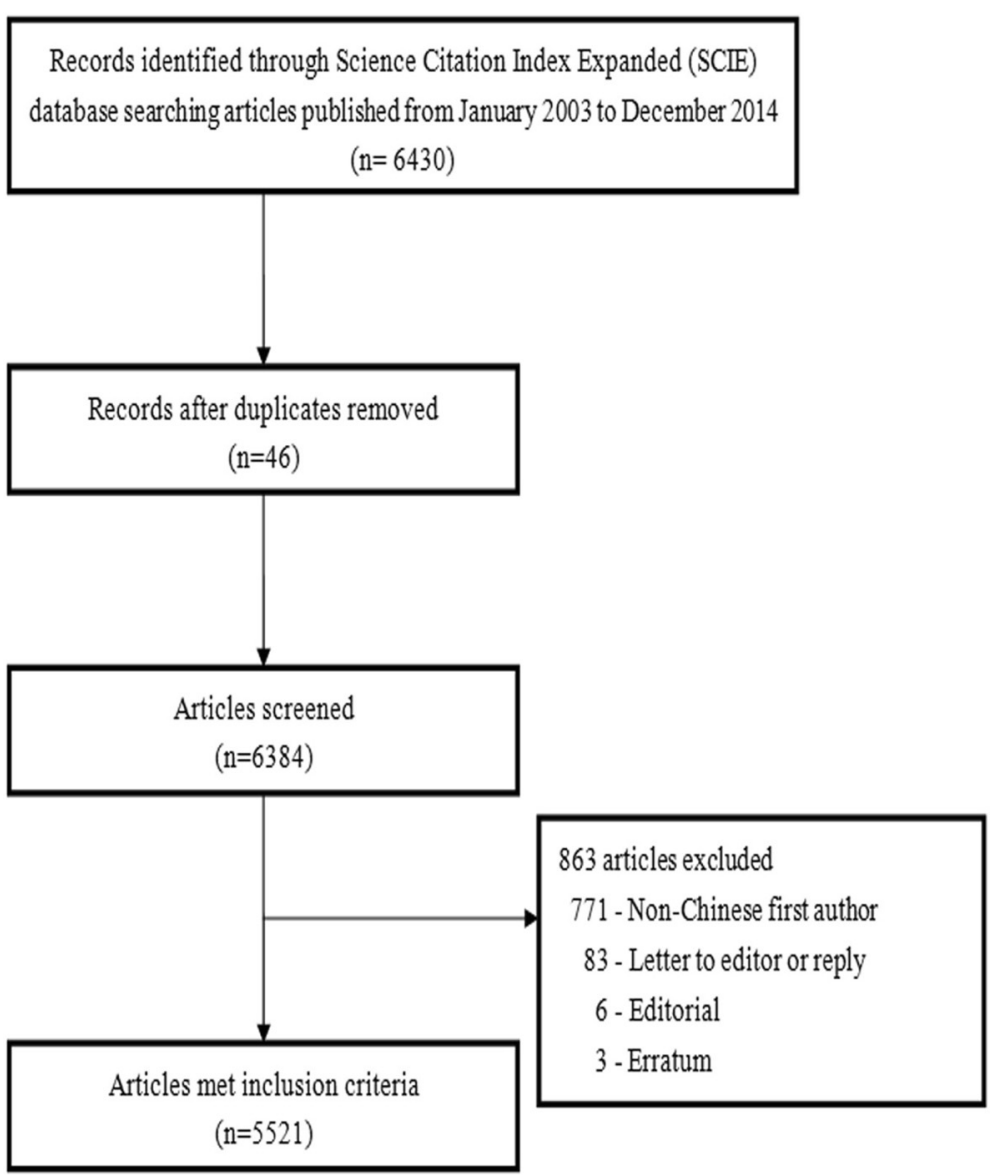

Fig. 1 Flow chart for study selection

Articles in the top 10 high IF orthopedics journals

A total of 1147 articles from the three regions were published in the top 10 high IF orthopedics journals. Among them, 20.84 \% (239/1147) were in the top 3 journals, including Journal of Bone and Joint Surgery American
Volume, American Journal of Sports Medicine, and Osteoarthritis and Cartilage. Researchers from mainland China published 518 articles (45.16\%) in the top 10 high IF orthopedics journals, those from Hong Kong published 193 articles (16.82\%), and those from Taiwan

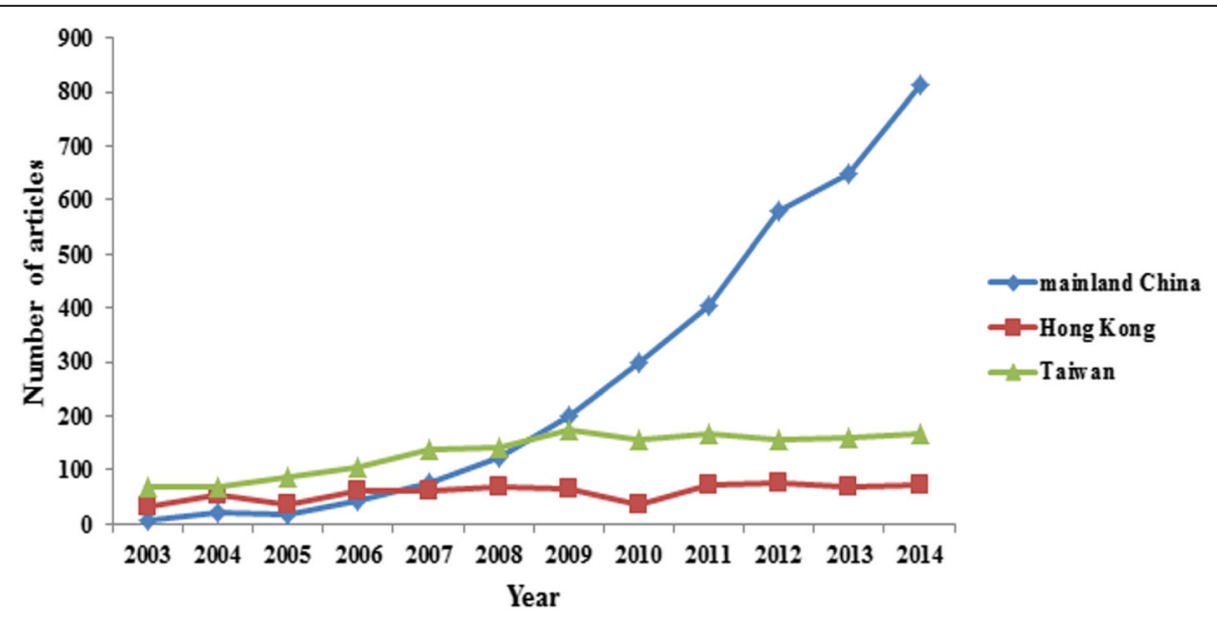

Fig. 2 Annual number of articles in the 63 orthopedics journals written by authors from mainland China, Hong Kong, and Taiwan (2003-2014) 


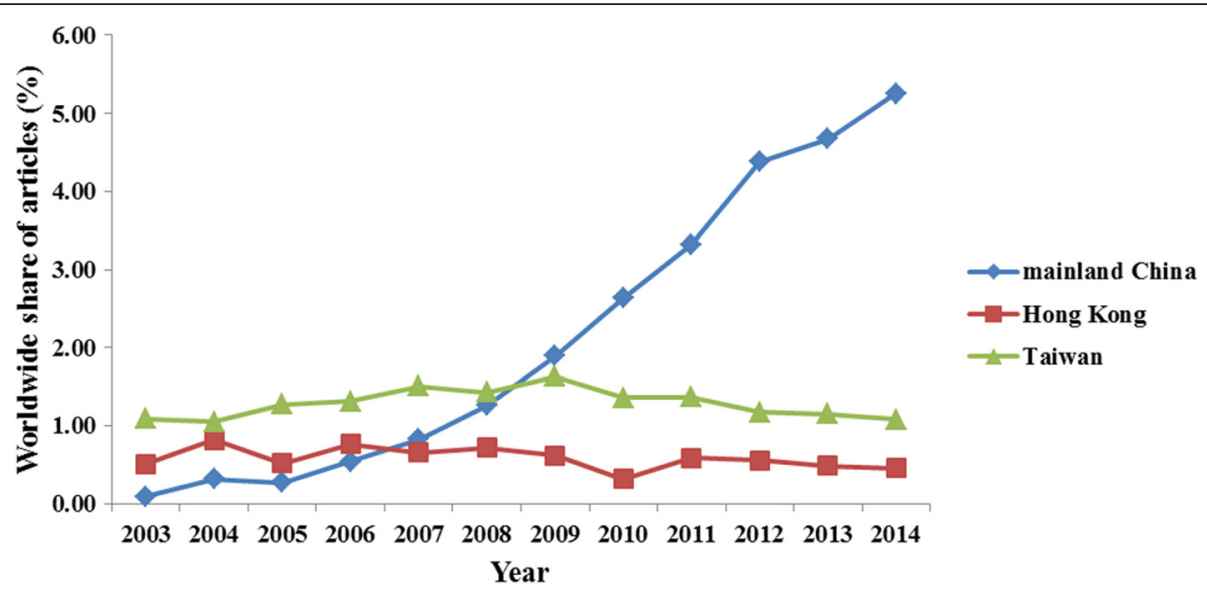

Fig. 3 Annual worldwide share of articles in the 63 orthopedics journals written by authors from mainland China, Hong Kong, and Taiwan (2003-2014)

published 436 articles (38.02 \%) (mainland China vs. Hong Kong, $P=0.003$; mainland China vs. Taiwan, $P=0.456$; Hong Kong vs. Taiwan, $P=0.017$ ) (Table 4).

\section{Top 10 popular orthopedics journals}

The journals that published the most articles written by orthopedist from the three regions are listed in Table 5. Over 12 years, Spine ranked the first in mainland China, Hong Kong, and Taiwan. Besides Spine, Injury and Journal of Orthopaedic Research also appeared in the list of most popular journals for all three regions.

\section{Most prolific and highly cited authors}

Researchers were ranked based on their number of articles and citations (Tables 6 and 7). Among the top 10 most published authors, 4 were from Taiwan, 3 were from mainland China, and 3 were from Hong Kong. The number of publications for the top 10 authors ranged from 84 articles (1st place) to 64 articles (10th place). Among the citation ranking of the top 10 authors, 4 were from Taiwan, 4 were from Hong Kong, and 2 were from mainland China. The number of citations for the top 10 authors ranged from 1625 (1st) to 810 (10th). Qiu Y, from mainland China, was the most prolific author, publishing 84 articles during the study period, while Wang CJ, from Taiwan, was the most-cited author (1625 citations). Seven of the top 10 prolific authors had citations within the top 10, including Luk KDK (Hong Kong), Chen Wen-Jong (Taiwan), Wang CJ (Taiwan), Chen Wen-Jer (Taiwan), Tang JB (mainland China), Cheung KMC (Hong Kong), and Chen TH (Taiwan). The orthopedist outside of the top 10 most

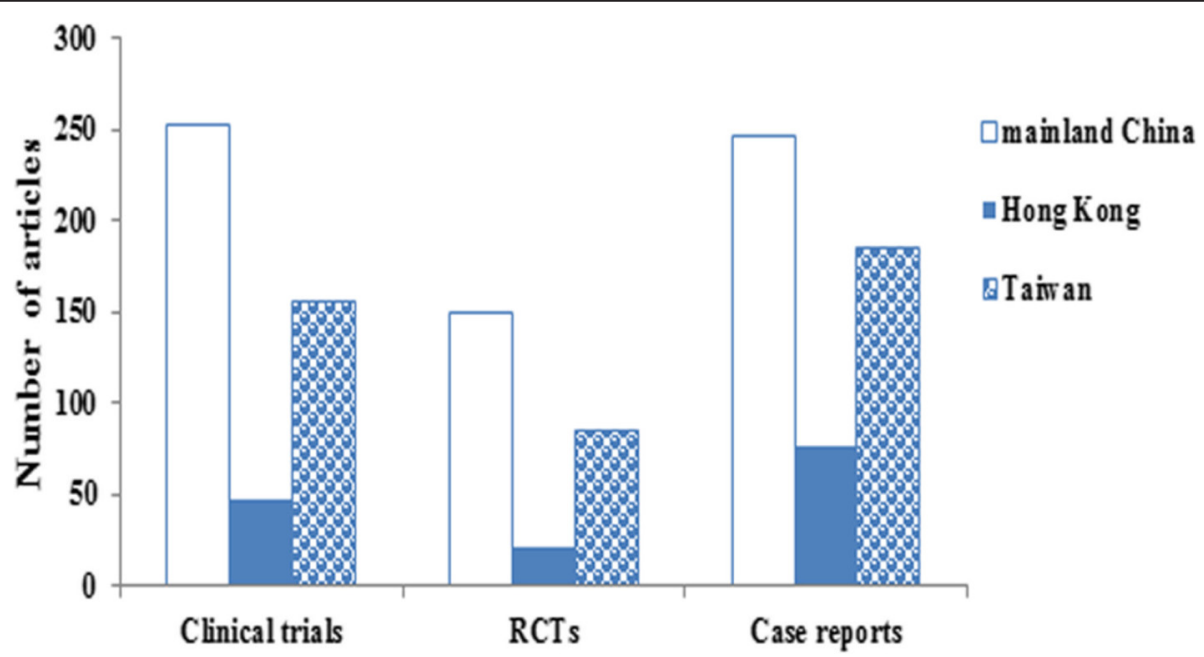

Fig. 4 Number of clinical trials, randomized controlled trials (RCTs), and case reports published by authors from mainland China, Hong Kong, and Taiwan (2003-2014) 
Table 2 The accumulated and average impact factors of articles from mainland China, Hong Kong, and Taiwan from 2003 to 2014

\begin{tabular}{|c|c|c|c|c|c|c|}
\hline \multirow[t]{2}{*}{ Year } & \multicolumn{3}{|c|}{ Accumulated impact factors } & \multicolumn{3}{|c|}{ Average impact factors } \\
\hline & Mainland China & Hong Kong & Taiwan & Mainland China & Hong Kong & Taiwan \\
\hline 2003 & 15.73 & 85.61 & 189.06 & 2.62 & 2.31 & 2.74 \\
\hline 2004 & 47.56 & 152.80 & 185.20 & 2.16 & 2.55 & 2.44 \\
\hline 2005 & 79.01 & 111.42 & 233.52 & 2.55 & 2.42 & 2.51 \\
\hline 2006 & 111.36 & 160.31 & 263.15 & 2.42 & 2.39 & 2.63 \\
\hline 2007 & 183.61 & 161.19 & 337.02 & 2.38 & 2.52 & 2.79 \\
\hline 2008 & 281.90 & 143.59 & 288.63 & 2.39 & 2.28 & 2.43 \\
\hline 2009 & 389.48 & 194.18 & 356.23 & 2.36 & 2.31 & 2.33 \\
\hline 2010 & 582.11 & 104.97 & 352.96 & 2.26 & 2.33 & 2.43 \\
\hline 2011 & 760.61 & 210.77 & 384.26 & 2.26 & 2.45 & 2.43 \\
\hline 2012 & 1089.37 & 208.48 & 313.43 & 2.23 & 2.32 & 2.37 \\
\hline 2013 & 1205.97 & 150.84 & 307.44 & 2.13 & 2.36 & 2.14 \\
\hline 2014 & 1450.62 & 187.30 & 310.87 & 2.07 & 2.40 & 2.27 \\
\hline Total & 6197.33 & 1871.46 & 3521.78 & 2.20 & 2.39 & 2.43 \\
\hline
\end{tabular}

published authors was not inevitably low in the citation rates of articles. For instance, the 60 articles by Cheng JCY (Hong Kong) ranked him in 12th place overall, but his articles ranked 6th in total number of citations $(n=1048)$. Qin L (Hong Kong) ranked 18th $(n=46)$ in number of articles and 9th $(n=878)$ in total number of citations.

\section{Most prolific and highly cited institutions}

Among the top 10 most prolific institutions, 4 were in mainland China, 4 were in Taiwan, and 2 were in Hong Kong (Tables 8 and 9). The number of publications by the top 10 institutions ranged from 421 articles (1st place) to 101 articles (10th place). The number of citations by the top 10 institutions ranged from 5500 (1st place) to 931 (10th place). Chang Gung Memorial Hospital was the most prolific institutional source of orthopedics articles, and also ranked first in the total number of citations. Eight of the top 10 prolific institutions had citations within the top 10, except for Changzheng Hospital and West China Hospital. However, the centers not in the top 10 most prolific institutions were not certainly low in the total citations of articles. For example, Xinhua Hospital affiliated to Shanghai Jiao Tong University School of Medicine ranked 18th in number of published articles $(n=70)$ and 8 th in total number of citations $(n=976)$.

Table 3 Total citations and average citations per article from mainland China, Hong Kong, and Taiwan from 2003 to 2014

\begin{tabular}{|c|c|c|c|c|c|c|}
\hline \multirow[b]{2}{*}{ Year } & \multicolumn{3}{|l|}{ Total citations } & \multicolumn{3}{|l|}{ Average citations } \\
\hline & Mainland China & Hong Kong & Taiwan & Mainland China & Hong Kong & Taiwan \\
\hline 2003 & 203 & 635 & 1461 & 33.83 & 19.84 & 21.49 \\
\hline 2004 & 596 & 990 & 1416 & 28.38 & 18.33 & 20.52 \\
\hline 2005 & 868 & 560 & 1760 & 45.68 & 15.56 & 20.00 \\
\hline 2006 & 1336 & 1073 & 2174 & 31.07 & 17.59 & 20.70 \\
\hline 2007 & 1273 & 1213 & 1780 & 16.97 & 20.22 & 12.99 \\
\hline 2008 & 1802 & 902 & 1653 & 14.65 & 12.89 & 11.81 \\
\hline 2009 & 2075 & 946 & 1907 & 10.32 & 14.33 & 11.02 \\
\hline 2010 & 2692 & 511 & 1281 & 8.97 & 14.19 & 8.26 \\
\hline 2011 & 2475 & 685 & 1022 & 6.11 & 9.51 & 6.12 \\
\hline 2012 & 2692 & 536 & 734 & 4.64 & 7.24 & 4.71 \\
\hline 2013 & 1995 & 187 & 461 & 3.07 & 2.75 & 2.88 \\
\hline 2014 & 716 & 108 & 111 & 0.88 & 1.52 & 0.66 \\
\hline Total & 18723 & 8346 & 15760 & 5.79 & 11.92 & 9.94 \\
\hline
\end{tabular}


Table 4 Articles published in the top 10 high IF orthopedics journals by researchers from mainland China, Hong Kong, and Taiwan from 2003 to 2014

\begin{tabular}{|c|c|c|c|c|c|c|}
\hline Rank & Journal & 2014 IF & Mainland China & Hong Kong & Taiwan & Total \\
\hline 1 & J Bone Joint Surg Am & 5.28 & 34 & 11 & 49 & 94 \\
\hline 2 & Am J Sport Med & 4.362 & 28 & 13 & 23 & 64 \\
\hline 3 & Osteoarthritis Cartilage & 4.165 & 46 & 6 & 29 & 81 \\
\hline 4 & J Bone Joint Srug Br & 3.309 & 35 & 10 & 30 & 75 \\
\hline 5 & Arthroscopy & 3.206 & 60 & 31 & 59 & 150 \\
\hline 6 & Knee Surg Sport Tr A & 3.053 & 82 & 27 & 26 & 135 \\
\hline 7 & J Orthop Res & 2.986 & 87 & 35 & 103 & 225 \\
\hline 8 & Acta Orthopaedica & 2.771 & 11 & 3 & 11 & 25 \\
\hline 9 & Clin Orthop Relat R & 2.765 & 68 & 30 & 56 & 154 \\
\hline 10 & Journal of Arthroplasty & 2.666 & 67 & 27 & 50 & 144 \\
\hline Total & & & 518 & 193 & 436 & 1147 \\
\hline
\end{tabular}

Kaohsiung Medical University ranked 14th in number of published articles $(n=82)$ and 9 th in total number of citations $(n=966)$.

\section{Discussion}

To the best of our knowledge, this is the first study to systematically analyze the quantity and quality of literature regarding orthopedics diseases from Chinese authors in the three regions (mainland China, Hong Kong, and Taiwan). Our study demonstrated that China had a consistent improvement in the field of orthopedics, and the numbers of articles published every year have increased markedly from 2003 to 2014. Worldwide there was also a persistent increase in the number of orthopedics publications during the past 12 years. Table 1 could give a general picture of the worldwide productivity in orthopedics research. It was very difficult to discuss about all countries mentioned in the Table 1 . Therefore, we only focused on the traditional scientific powers and rapidly emerging scientific powers, which made a major contribution to the field of orthopedics. There is no doubt that the total and annual numbers of orthopedics publications from USA were the highest in the world. In the past 12 years, the annual number of published articles increased steadily in highly developed countries including the UK, Japan, Germany, and Canada. Of note, there was a dramatic increase in the annual number of published articles in China and South Korea. On the other hand, publications per million (the ratio of the number of publications to the population of a country) was one of the parameters used in the measurement of scientific productivity of a community. Small highly developed countries, such as Denmark, Finland, Sweden, and the Netherlands, all ranked in the top in respect to orthopedics publications per million, and outperformed larger highly developed counterparts including USA, Germany, and Japan [9-11]. Given the relative size of the populations, China lagged far behind the most productive countries in the field of orthopedics.

Table 5 Top 10 orthopedics journals publishing the most articles written by authors from mainland China, Hong Kong, and Taiwan from 2003 to 2014

\begin{tabular}{llllllllll}
\hline Rank & Mainland China & IF & N & Hong Kong & IF & N & Taiwan & IF & N \\
\hline 1 & Spine & 2.297 & 327 & Spine & 2.297 & 83 & Spine & 2.297 & 127 \\
2 & ESJ & 2.066 & 267 & JOR & 2.986 & 35 & JOR & 2.986 & 103 \\
3 & IO & 2.11 & 254 & ARTH & 3.206 & 31 & Injury & 2.137 & 93 \\
4 & ORTH & 0.962 & 180 & CORR & 2.765 & 30 & ARTH & 3.206 & 59 \\
5 & AOTS & 1.597 & 151 & Injury & 2.137 & 29 & CORR & 2.765 & 56 \\
6 & Injury & 2.137 & 137 & KSSTA & 3.053 & 27 & JOA & 2.666 & 56 \\
7 & JSDT & 2.202 & 134 & JOA & 2.666 & 27 & ORTH & 0.962 & 55 \\
8 & JOR & 2.986 & 87 & IO & 2.11 & 27 & AOTS & 1.31 & 53 \\
9 & KSSTA & 3.053 & 82 & FAl & 1.506 & 24 & BMD & 1.717 & 53 \\
10 & JHSA & 1.667 & 80 & TSJ & 2.426 & 17 & JBJSA & 5.28 & 49 \\
\hline
\end{tabular}

Abbreviations: ESJ Eur Spine J, IO Int Orthop, ORTH Orthopedics, AOTS Arch Orthop Traum Su, JSDT J Spinal Disord Tech, JOR J Orthop Res, KSSTA Knee Surg Sport $\operatorname{Tr}$ A, JHSA J Hand Surg Am, ARTH Arthroscopy, CORR Clin Orthop Relat R, JOA J Arthroplasty, FAl Foot Ankle Int, TSJ Spine J, BMD BMC Musculoskel Dis, JBJSA J Bone Joint Surg Am 
Table 6 Top 10 authors, according to the number of articles from 2003 to 2014

\begin{tabular}{|c|c|c|c|c|c|c|}
\hline Rank & Author & No. of articles & No. of citations & Average citation & $H$-index & Region \\
\hline 1 & Qiu Yong & 84 & 536 & 6.38 & 12 & $M L$ \\
\hline 2 & Luk Keith D.K. & 82 & 1274 & 15.54 & 20 & HK \\
\hline 3 & Chen Wen-Jong & 76 & 1134 & 14.92 & 22 & TW \\
\hline 4 & Lui Tun Hing & 75 & 362 & 4.83 & 10 & HK \\
\hline 5 & Wang Ching-Jen & 71 & 1625 & 22.89 & 22 & TW \\
\hline 6 & Chen Wen-Jer & 70 & 1074 & 15.34 & 21 & TW \\
\hline 7 & Tang Jingbo & 67 & 967 & 14.43 & 18 & $M L$ \\
\hline 8 & Yuan Wen & 65 & 327 & 5.03 & 10 & $M L$ \\
\hline 9 & Cheung Kenneth M. C. & 65 & 1136 & 17.48 & 19 & HK \\
\hline 10 & Chen Tain-Hsiung & 64 & 810 & 12.66 & 15 & TW \\
\hline
\end{tabular}

Abbreviations: ML mainland China, HK Hong Kong, TW Taiwan

As it was a British Colony since the middle of the 19th century, Hong Kong has a long history of internationalization and a high degree of modern science and education level. Taiwan was one of the famous Newly Industrial Economics countries from the 1970s, whose advanced scientific and academic systems mixed features of China and America. For many years, scientific and medical research from Hong Kong and Taiwan has a world-class performance, and has been more advanced than that from mainland China. In fact, researchers from these two regions have contributed some of the best scientific articles on orthopedics. On the other hand, orthopedics in mainland China has made a great progress since the beginning of the 21st century. Its rapid growth has occurred in the recent 12 years due to the implementation of reform and open policy, and with the opening of China's doors to the international community. In accordance with previous studies in other disciplines $[12,13]$, our results clearly demonstrated that scientific publication by mainland China investigators in international orthopedics periodicals increased dramatically during this period. Specifically, the annual number and worldwide share of articles from mainland China has exceeded that from Hong Kong since 2007 and surpassed that from Taiwan in 2009. The number of articles from Hong Kong increased rapidly from 2003 to 2006, and this number has plateaued since 2006. An increasing trend in the number of articles from Taiwan was found between 2003 and 2009 and remained steady at the end of the study period.

Mainland China had the largest number of clinical trials, RCTs, and case reports during the past 12 years. Historically, investigators from Taiwan have contributed a great number of clinical trials and RCTs in the field of orthopedics. However, the annual number of such studies from researchers in mainland China has been ahead of the three regions since 2010. In addition, the numbers of published case reports from mainland China also far exceeded those from Hong Kong and Taiwan. There are several reasons that clinical research in mainland China has proceeded at a fast speed. First, China is a large country, with the largest population in the world and a vast number of patients suffering from orthopedics

Table 7 Top 10 authors, according to the number of citations from 2003 to 2014

\begin{tabular}{|c|c|c|c|c|c|c|}
\hline Rank & Author & No. of citations & No. of articles & Average citation & $H$-index & Region \\
\hline 1 & Wang Ching-Jen & 1625 & 71 & 22.89 & 22 & TW \\
\hline 2 & Luk Keith D.K. & 1274 & 82 & 15.54 & 20 & $\mathrm{HK}$ \\
\hline 3 & Cheung Kenneth M.C. & 1136 & 65 & 17.48 & 19 & HK \\
\hline 4 & Chen Wen-Jong & 1134 & 76 & 14.92 & 22 & TW \\
\hline 5 & Chen Wen-Jer & 1074 & 70 & 15.34 & 21 & TW \\
\hline 6 & Cheng Jack C.Y. & 1048 & 60 & 17.47 & 18 & $\mathrm{HK}$ \\
\hline 7 & Tang Jingbo & 967 & 67 & 14.43 & 18 & ML \\
\hline 8 & Dai Li-Yang & 908 & 57 & 15.93 & 19 & $M L$ \\
\hline 9 & Qin Lin & 878 & 46 & 19.09 & 17 & $\mathrm{HK}$ \\
\hline 10 & Chen Tain-Hsiung & 810 & 64 & 12.66 & 15 & TW \\
\hline
\end{tabular}

Abbreviations: TW Taiwan, HK Hong Kong, ML mainland China 
Table 8 Top 10 institutions, according to the number of articles from 2003 to 2014

\begin{tabular}{|c|c|c|c|c|c|c|}
\hline Rank & Institution & No. of articles & No. of citations & Average citations & $H$-index & Region \\
\hline 1 & Chang Gung Mem Hosp & 421 & 5500 & 13.06 & 34 & TW \\
\hline 2 & Prince Wales Hosp & 244 & 3192 & 13.08 & 31 & HK \\
\hline 3 & Vet Gen Hosp & 226 & 2299 & 10.17 & 26 & TW \\
\hline 4 & Natl Taiwan Univ Hosp & 185 & 2048 & 11.07 & 23 & TW \\
\hline 5 & Queen Mary Hosp & 153 & 1795 & 11.73 & 24 & HK \\
\hline 6 & Natl Cheng Kung Univ & 148 & 1419 & 9.59 & 18 & TW \\
\hline 7 & Changzheng Hosp & 146 & 780 & 5.34 & 16 & $M L$ \\
\hline 8 & Shanghai Peoples Hosp 6 & 131 & 931 & 7.11 & 16 & $M L$ \\
\hline 9 & West China Hosp & 130 & 735 & 5.65 & 12 & $M L$ \\
\hline 10 & Peking Univ Hosp 3 & 101 & 992 & 9.82 & 16 & ML \\
\hline
\end{tabular}

Abbreviations: TW Taiwan, HK Hong Kong, ML mainland China

diseases. Second, people in mainland China may be more compliant towards engagement in clinical research protocols. Third, clinical trials in mainland China are much less costly to carry out [14]. Fourth, controlled clinical studies have been an important research direction of Chinese orthopedists in recent years [15].

The annual total IFs of articles originating in China has increased significantly over the past 12 years, and has surpassed Taiwan and Hong Kong since 2009. However, the average IFs of articles from mainland China still lags behind those from Taiwan and Hong Kong. It should also be mentioned that IFs are not the only or optimal parameters for determining the quality of articles [16]. The number of times an article has been cited represents the degree of its influence on other publications and was adopted in this study as an indicator of the impact and quality of articles. Articles from mainland China were cited most, those from Taiwan were cited second-most, and those from Hong Kong were cited the least. However, the average citations per article of publications from mainland China were markedly lower than those from Taiwan and Hong Kong. Mainland China witnessed a rapid increase in the number of published orthopedics articles, but its total and average citations per article were small. This phenomenon could be explained by two reasons. On one hand, mainland China published 2042 articles in the most recent 3 years, accounting for $63.12 \%(2042 / 3235)$ of the total number of articles published during 2003 to 2014. Obviously, the older an article is, the more likelihood it has of being cited. On the other hand, this may reflect the fact that quality of articles from mainland China needs to be improved significantly.

As far as the top 10 high IF orthopedics journals are concerned, researchers from mainland China (518 articles) and Taiwan (436 articles) published more papers than those from Hong Kong (193 articles). In the present study, Spine, Injury, and Journal of Orthopaedic Research were found to be the most popular journals for authors from mainland China, Hong Kong, and Taiwan and were in the list of the top 10 most popular journals in all three regions. These journals are the oldest publications for the specialty of orthopedics, and have an established and proud history of publishing top-class scientific articles in the field. During the past 12 years,

Table 9 Top 10 institutions, according to number of citations from 2003 to 2014

\begin{tabular}{|c|c|c|c|c|c|c|}
\hline Rank & Institution & No. of citations & No. of articles & Average citations & $H$-index & Region \\
\hline 1 & Chang Gung Mem Hosp & 5500 & 421 & 13.06 & 34 & TW \\
\hline 2 & Prince Wales Hosp & 3192 & 244 & 13.08 & 31 & $\mathrm{HK}$ \\
\hline 3 & Vet Gen Hosp & 2299 & 226 & 10.17 & 26 & TW \\
\hline 4 & Natl Taiwan Univ Hosp & 2048 & 185 & 11.07 & 23 & TW \\
\hline 5 & Queen Mary Hosp & 1795 & 153 & 11.73 & 24 & HK \\
\hline 6 & Natl Cheng Kung Univ & 1419 & 148 & 9.59 & 18 & TW \\
\hline 7 & Peking Univ Hosp 3 & 992 & 101 & 9.82 & 16 & $M L$ \\
\hline 8 & Xinhua Hosp & 976 & 70 & 13.94 & 20 & $\mathrm{ML}$ \\
\hline 9 & Kaohsiung Med Univ & 966 & 82 & 11.78 & 16 & TW \\
\hline 10 & Shanghai Peoples Hosp 6 & 931 & 131 & 7.11 & 16 & ML \\
\hline
\end{tabular}

Abbreviations: TW Taiwan, HK Hong Kong, ML mainland China 
537 articles from Chinese authors were published in Spine, 259 articles were published in Injury, and 225 articles were published in Journal of Orthopaedic Research. Recently, the introduction of a Chinese-language edition of high-level journals may have increased authors' interest in publishing articles in these journals, which have certainly promoted the development of orthopedics research in China and contributed to China taking its place in the field of orthopedics.

An analysis of prolific authors in orthopedics showed that Taiwan had 4 most prolific authors, and mainland China and Hong Kong each had 3 most prolific authors. Furthermore, Taiwan and Hong Kong both had 4 mostcited orthopedics researchers, and mainland China had 2 most-cited orthopedics researchers. An analysis of the top 10 research institutions found that the mainland China and Taiwan each had the 4 top research institutions for orthopedics, while Hong Kong had 2 top research institutions. However, the top 6 research institutions all came from Taiwan and Hong Kong. Except for West China Hospital, three of four top research institutions from mainland China were located in the southeast coastal region that was considered as the most developed area of China. It is objective fact that the development of medicine in eastern and western China exist the regional disparity. In Taiwan, the Chang Gung Memorial Hospital has been considered a "powerhouse", which published 421 articles with 5500 citations, accounting for $26.5 \%$ of Taiwan's publications.

Publications in the medical field that reach an international audience mainly depend on excellent research and English fluency. This has given a major advantage to "English-speaking" or developed regions. Hong Kong, as a previous British colony, has the superiority of having a strong foundation in written English. In contrast, Taiwan is generally better known for having one of the best research environments in East Asia, owing to its socioeconomic development. Thus, academic institutions from Hong Kong and Taiwan have been able to publish more high-quality papers in orthopedics science. In recent years, mainland China has narrowed the gap, and has even overtaken the Hong Kong and Taiwan, at least in terms of the number of articles published in international orthopedics journals. However, the most prolific authors and top research institutions from mainland China still lag behind those from Hong Kong and Taiwan in terms of citations per article. Our study indicates that mainland China has come a long way and still has some distance to achieve the academic productivity of Hong Kong and Taiwan.

Several factors favor mainland China's immense growth in orthopedics research. First, as the recent advances in China's economy, the public are beginning to raise awareness of bone and joint disease [17]. Many new institutions and hospitals in mainland China have started basic and clinical research in the orthopedics fields [18]. Second, international collaborations may help Chinese orthopedics investigators to improve their clinical orthopedics practice and research capabilities, and make it possible for overseas scholars to understand the development of orthopedics science in mainland China. Third, in recent years, Chinese government authorities have begun to advocate for the use of IFs and citations when evaluating the performance of individual scientists. This has now been regarded as an important indicators used to measure their scientific contributions, which is closely related to academic status, income, funding, and other important benefits [19]. Subsequently, scientists have endeavored to publish their research in SCIE journals.

This study has limitations that should be highlighted. First, only the 63 orthopedics journals covered by the SCIE database were analyzed. Some orthopedics articles are published in general medical journals and were not included in this study. Second, the SCIE database is an English-language resource and has a publication bias. Many articles published in the journals from non-English speaking countries that were not indexed in this database. Thus, the contribution of non-English-language publications may have been underestimated. Third, the orthopedics journals were selected from the orthopedics category of SCIE database, and the IFs were evaluated by JCR 2014. In the past 12 years, the included journals and IF of the journals have changed year by year.

\section{Conclusions}

In conclusion, this study provides a novel overview of current Chinese orthopedics research. The annual number of articles published from mainland China has increased markedly during the past 12 years, particularly since 2007 . Concurrently, the number of publications from Hong Kong and Taiwan is growing at a slow and steady rate. Publications from mainland China had the highest accumulated IF and total citations of articles. Publications from Taiwan had the highest average citations per article, and publications from Hong Kong had the highest average IFs. Taking into consideration the relative size of the populations, it should be emphasized that mainland China still has a long way to go to achieve the academic performance of Hong Kong and Taiwan.

\section{Abbreviations}

IFs, impact factors; RCTs, randomized controlled trials; SCIE, science citation index expanded

\section{Acknowledgements}

This work was supported by the Natural Science Foundation of China (81460353/81460349/81560371), Guangxi Natural Science Foundation (2015GXNSFBA139167) and Youth Science Foundation of Guangxi Medical University (GXMUYSF201329). 


\section{Funding}

Not applicable.

\section{Availability of data and materials} Not applicable.

\section{Authors' contributions}

ZX conceived and designed the study. HJ was involved in data search and selection of data, analyzed the data and wrote the manuscript. BN was involved in data search, selection of data and analyzed the data. LY was involved in data search and analyzed the data. SZ was involved in data search and selection of data. XZ and QW analyzed the data and contributed analysis tools. All authors read and approved the final manuscript.

\section{Competing interests}

The authors declare that they have no competing interests.

\section{Consent for publication}

Not applicable.

\section{Ethics approval and consent to participate}

Not applicable.

\section{Author details}

'Department of Orthopedic Surgery, The First Affiliated Hospital of Guangxi Medical University, Shuangyong Road No. 6, Nanning 530021, China. ${ }^{2}$ Library of Medicine, Guangxi Medical University, Nanning, China.

\section{Received: 10 January 2016 Accepted: 14 June 2016}

Published online: 17 June 2016

\section{References}

1. Tong D, Wang $L$, Jiang J. Publications from China in The Lancet, NEJM, and JAMA. Lancet. 2013;381:1983.

2. Goh KL, Farrell GC. Publications from China: the sleeping giant awakens. J Gastroenterol Hepatol. 2008;23:341-3.

3. Wei M, Wang W, Zhuang Y. Worldwide research productivity in the field of spine surgery: a 10-year bibliometric analysis. Eur Spine J. 2016;25:976-82.

4. Ajuied A, Back D, Smith C, Davies AJ, Wong F, Earnshaw PH. Publication trends in knee surgery: a review of the last 16 years. J Arthroplasty. 2013;28:751-8.

5. Gurbuz Y, Sugun TS, Ozaksar K. A bibliometric analysis of orthopedic publications originating from Turkey. Acta Orthop Traumatol Turc. 2015;49:57-66.

6. Kawaguchi Y, Guarise da Silva P, Quadros FW, Merlin LH, Radaelli L, Guyot JP, Dozza D, Martins D, Scheverin N, Riew DK, et al. Analysis of scientific output by spine surgeons from Japan: January 2000 to December 2013. J Orthop Sci. 2016;21:13-8.

7. Ye B, Du TT, Xie T, Ji JT, Zheng ZH, Liao Z, Hu LH, Li ZS. Scientific publications in respiratory journals from Chinese authors in various parts of North Asia: a 10-year survey of literature. BMJ Open. 2014:4:e004201.

8. ISI Journal Citation Reports, Institute for Scientific Information, 2014. Available from http://isiknowledge.com. Accessed 2015 Stp 1st.

9. Moit JS, Sutherland AG, Maffulli N. International orthopaedic journals: a 15-year review. J Bone Joint Surg Br. 1998;80:6-8.

10. Luo X, Liang Z, Gong F, Bao H, Huang L, Jia Z. Worldwide productivity in the field of foot and ankle research from 2009-2013: a bibliometric analysis of highly cited journals. J Foot Ankle Res. 2015;8:12.

11. Liang Z, Luo X, Gong F, Bao H, Qian H, Jia Z, Li G. Worldwide research productivity in the field of arthroscopy: a bibliometric analysis. Arthroscopy. 2015;31:1452-7

12. Zhang $L$, Ye $X$, Sun $Y$, Deng AM, Qian BH. Hematology research output from Chinese authors and other countries: a 10-year survey of the literature. J Hematol Oncol. 2015;8:8.

13. Li M, Liu X, Zhang L. Scientific publications in public, environmental and occupational health journals by authors from China, Japan and Korea in East Asia: a 10-year literature survey from 2003 to 2012. Int J Occup Med Environ Health. 2015;28:663-73.

14. Guo L. China boosts medical research. Lancet. 2010;375:711.

15. Leung KS, Ngai WK, Tian W. Orthopaedic training in China: experiences from the promotion of orthopaedic specialist training in China. J Bone Joint Surg Br. 2011;93:1165-8.
16. Wang D, Song C, Barabasi AL. Quantifying long-term scientific impact. Science. 2013:342:127-32.

17. Eom SH, Bamne AB, Chowdhry M, Chae IS, Kim TK. Bibliometric analysis of orthopedic literature on total knee arthroplasty in Asian countries: a 10-year analysis. Knee Surg Relat Res. 2015;27:149-55.

18. Jia Z, Wu Y, Tang Y, Ji W, Li W, Zhao X, Li H, He Q, Ruan D. Equal contributions and credit: an emerging trend in the characterization of authorship in major spine journals during a 10-year period. Eur Spine J. 2016:25:913-7.

19. Yuan HF, Xu WD, Hu HY. Young Chinese doctors and the pressure of publication. Lancet. 2013:381:e4.

\section{Submit your next manuscript to BioMed Central and we will help you at every step:}

- We accept pre-submission inquiries

- Our selector tool helps you to find the most relevant journal

- We provide round the clock customer support

- Convenient online submission

- Thorough peer review

- Inclusion in PubMed and all major indexing services

- Maximum visibility for your research

Submit your manuscript at www.biomedcentral.com/submit 